\title{
Design and Test of HTS Coils for Resistive Fault Current Limiter
}

\author{
C. A. Baldan, C. Y. Shigue, D. G. Pinatti, E. Ruppert-Filho, R. C. Freitas, and R. P. Homrich
}

\begin{abstract}
This paper presents the design, manufacturing and test results of HTS coils for single-phase resistive current limiters using two different Bi-2223/Ag tapes. Two coils were separately wound on cylindrical G-10 tubes with helical path. One of the coil was wound in a bifilar conductor arrangement aiming at reducing the self-inductance. The maximum flux density is $40 \mathrm{mT}$ on the HTS tape for both coils and the calculated inductance is $5.76 \mu \mathrm{H}$ for the noninductively wound coil and $28.3 \mu \mathrm{H}$ for the conventional one. The two coils were individually tested under DC and AC currents. The DC power loss was calculated from the measured voltage-current values product and the $\mathrm{AC}$ power loss was determined by the liquid nitrogen mass boil-off measurement. The acquired voltage AC waveforms were analyzed through the separation of distinct contributions due to magnetic flux and to a resistive component in-phase with the current. It was observed an inflection point common to the $\mathrm{DC}$ and $\mathrm{AC}$ power losses curves close to $I_{c}$ attributed to the $\mathrm{AC}$ transition current.
\end{abstract}

Index Terms-Fault current limiter, HTS applications, HTS coils, resistive current limiter.

\section{INTRODUCTION}

$\mathbf{S}$ UPERCONDUCTING fault current limiters (SFCL) are one of the most promising device as an effective solution to reduce the increasing fault current level in power transmission networks where the prospective fault current level is becoming higher than the capacity of the circuit breakers. The SFCL using low temperature superconductors (LTS) had been studied in two conceptual designs: the resistive and the inductive ones [1]. However, due to high cooling costs for operation at $4.2 \mathrm{~K}$ they have not achieved economic feasibility.

The SFCL employing high temperature superconductors (HTS) have been under intensive research in different design concepts including resistive, inductive or hybrid and with different materials including $\mathrm{Bi}-2223$ wires and tapes, and YBCO films and bulk. In this paper we present the results of HTS test coils made of Bi-2223 tapes wounded on several concentric single layer coils connected in series and in noninductive winding.

Manuscript received October 21, 2003. This work was supported in part by the Companhia Paulista de Força e Luz-CPFL under Grant 4600000767.

C. A. Baldan, C. Y. Shigue, and D. G. Pinatti are with the Faculdade de Engenharia Química de Lorena (FAENQUIL), Departamento de Engenharia de Materiais (DEMAR), Lorena, SP, Brazil (e-mail: cabaldan@ demar.faenquil.br).

E. R. Filho and R. C. Freitas are with the Faculdade de Engenharia Elétrica e da Computação-FEEC, Universidade Estadual de Campinas, UNICAMP, Campinas, SP, Brazil (e-mail: ruppert@fee.unicamp.br).

R. P. Homrich is with the Departamento de Engenharia Elétrica (DEE), Universidade Federal do Rio Grande do Sul (UFRGS), Porto Alegre, RS, Brazi (e-mail: homrich@iee.ufrgs.br).

Digital Object Identifier 10.1109/TASC.2004.830303

\section{BASIC DESIGN}

In the design of a resistive SFCL with low impedance for a strongly interconnected power grid we should consider the parameters of conventional limiters such as the final resistance during fault producing maximum voltage drop below than $5 \%$ of the guaranteed value. The limiting factor can be defined by the ratio between the fault current $I_{p f}$ and the rated current $I_{n}$ as $I_{p f} / I_{n}>2.55$. For a $20 \mathrm{MVA} / 13.8 \mathrm{kV}$ capacity, the short circuit rated current per phase is $I_{S C}=800 \mathrm{~A}$ and the impedance to limit the power rising up to $150 \%$ during short circuit by the FCL must be higher than $\mathrm{Z}_{\mathrm{r}}=9.6 \Omega$.

The limiting of the fault current must occur before it reaches the peak value by a fast quench (few milliseconds) of the superconducting winding. During the fault the current can exceed by up to 100 times the rated current and the circuit breakers of the conventional power system may have not designed for these levels of mechanical and thermal stresses. Using the conventional air-core reactors connected in series, the system impedance increases and the circuit breakers can interrupt the current between 20 and $300 \mathrm{~ms}$.

In a previous work [2], using LTS wire ( $\mathrm{NbTi} / \mathrm{CuNi}$ matrix) with $95 \mathrm{~m}$ length we achieved electrical resistance in the coil of $9.43 \Omega$ at $4.2 \mathrm{~K}$, the quench current achieved $434 \mathrm{~A}$ and the rated current $I_{S C}=800 \mathrm{~A}$ could be conducted easily with the coils connected in parallel.

The FCL coils employing Bi-2223 tapes with Ag/AgMg matrix show very low resistance at $77 \mathrm{~K}$ in the normal state and long length of conductor will be necessary $(\sim 250 \mathrm{~m})$ for a singlelayer coil to achieve resistance of $1.5 \Omega$ at $100 \mathrm{~K}$ and it will display lower rated current compared with the desirable value, i.e., 800 A for a 20 MVA unit.

For three concentric coils connected in parallel we could increase the transport current higher than $150 \%$ the rated current under safe condition during few seconds $(\sim 3 \mathrm{~s})$ at the expense of a long tape length $(\sim 2000 \mathrm{~m})$. The total AC losses are the limiting factors for the design of resistive SFCL and the development of tapes with higher resistivity matrix associated with lower filament twist-pitch is expected to reduce the losses down to $0.4 \mathrm{~mW} / \mathrm{A} . \mathrm{m}$ level for operation at $60 \mathrm{~Hz}$ [3].

\section{EXPERIMENTAL SETUP}

Table I shows the parameters of conductors and coils used to evaluate the designed values and performance of HTS conductor when AC current is applied.

The coils were constructed using G-10 tube on which one or two channels were machined in a helical path and the tape was 
TABLE I

Characteristics OF THE Bi-2223/Ag TAPES AND tHE TeSt CoILS

\begin{tabular}{lcc}
\hline \hline & Tape I & Tape II \\
\hline Width $(\mathrm{mm})$ & 4.0 & 4.1 \\
Thickness (mm) & 0.22 & $0.21(0.31)$ \\
Critical current (A) & 65 & 115 \\
Filling factor & $30 \%$ & $38 \%(25 \%)$ \\
\hline \multicolumn{1}{c}{ Coil I } & Coil II \\
\hline Coil diameter (mm) & 160 & 140 \\
Coil height (mm) & 245.3 & 283.4 \\
Total turns & $19+19$ & 22 \\
Conductor length (m) & 19.2 & 9.7 \\
Helical path (mm) & 6.35 & 12.7 \\
Inductance (H) & 5.76 & 28.3 \\
Critical current (A) & 62 & 110 \\
\hline \hline
\end{tabular}



Fig. 1. Schematic diagram of the circuit for AC current experiment with the oscilloscope ungrounded.

wound with low tensile stress applied. The coil I was wound with tape I in a bifilar conductors arrangement (noninductively). The coil II was wound with tape II in a single conductor arrangement.

The current leads connection and the joint within the coil are machined in a copper part insert placed on the G-10 tube before the helical path preparation in order to avoid any tape deformation besides that introduced by the curvature radius. For the soldering process the copper part was heated and maintained at $100^{\circ} \mathrm{C}$ and a low melting point alloy solder with citric acid as a flux is used.

The magnetic field distribution was calculated using 3-D software package Amperes [4] and the maximum self-field at the surface of the tape for critical current value is around $40 \mathrm{mT}$ for both coils. The self inductance of each coil was calculated using the same software taking into account the helical path of the conductor.

Fig. 1 shows the schematic diagram of the circuit for the measurements of the transport current loss in the coils. The voltage and current were measured at the voltage tap and by a current transformer, respectively. For the coils characterization under $\mathrm{AC}$ currents the voltage and current values are acquired using an ungrounded Tektronix TDS5054 digital storage oscilloscope with isolation amplifier. The AC current was applied using a $24 \mathrm{kVA} / 220 \mathrm{~V}$ variable autotransformer (variac) with a shunt resistor to adjust the current value.

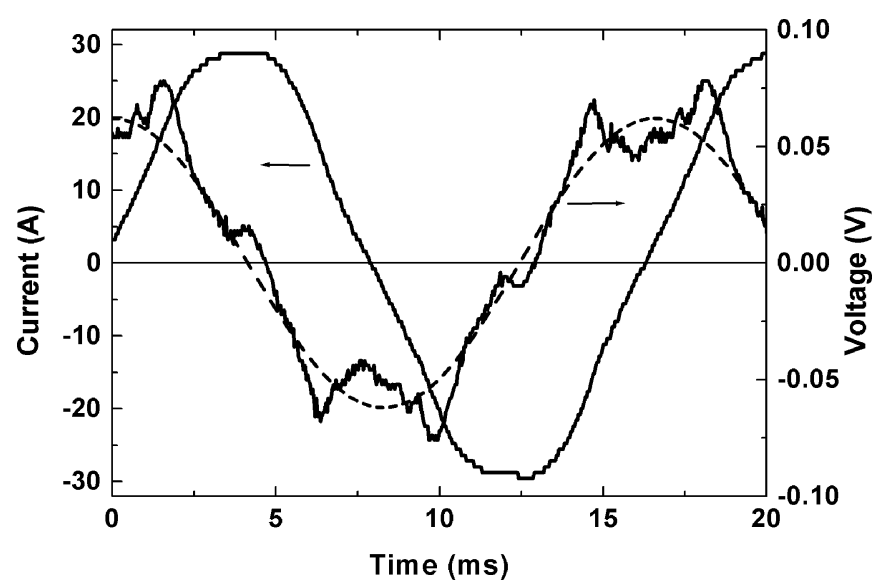

Fig. 2. Voltage and current signals for $I_{r m s}=20 \mathrm{~A}$. The dashed curve is a fitted waveform considering pure inductance contribution with $\cos \varphi=0.25$.

For the test under DC current, a programmable current supply EMI30 V/333 A was used along with a Keithley DMM2001 as a data acquisition unit for current and voltage measurements.

The total AC power losses, including contribution from magnetization, self-field and transport current were evaluated by $\mathrm{LN}_{2}$ mass boil-off rates for periods over $1 \mathrm{~h}$ for each current value by measuring the mass loss of liquid nitrogen from the cryostat. The contribution of metallic parts and current leads (for each current value) was properly subtracted [5].

The DC power losses were calculated from the I-V measurements by multiplying the electric field (voltage/length) by the current values.

\section{RESULTS AND DISCUSSION}

\section{A. Coil I}

The coil I has critical current under self-field $I_{c}=62 \mathrm{~A}$ or $95 \%$ of the measured value for short sample. The voltage taps are placed $100 \mathrm{~mm}$ far apart from the current leads and in the neighbor conductors in order to reduce the induced voltages.

The Figs. 2-4 show the voltage and current signals for $\mathrm{rms}$ current levels of $20 \mathrm{~A}, 40 \mathrm{~A}$, and $80 \mathrm{~A}$. The voltage waveforms were compared with a fitted sinusoidal curve due to the contribution of the calculated pure inductance of $5.76 \mu \mathrm{H}$. From the curves a phase angle between the voltage and the current waveforms can be seen. The phase angle was calculated from the inductive voltage waveforms (dashed curves) and the measured current curves.

For comparison purposes, we will use the critical current $I_{c}$ measured under DC condition. For current level $I_{r m s}<I_{c}$, the waveforms present many peaks without significant change in phase angle. In Fig. 3 is shown a peak related to the resistive contribution to the AC losses.

As the current level increases above $I_{c}$, we can observe that the pointed peak grows in phase with the current signal, thus corresponding to a resistive contribution to the voltage after superconductor/normal transition has occurred. This resistive contribution becomes higher than the other AC losses contributions. 


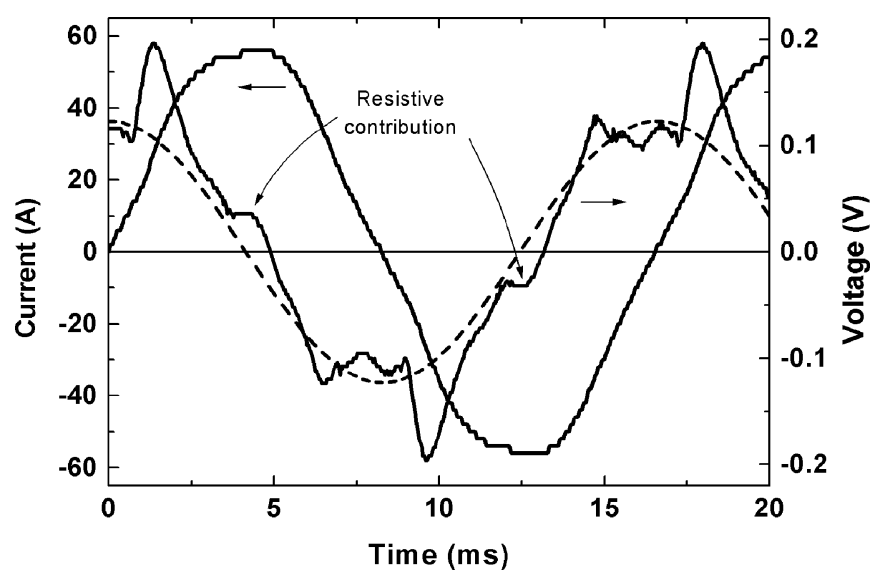

Fig. 3. Voltage and current signals for $I_{r m s}=40 \mathrm{~A}$. The dashed curve is a fitted waveform considering pure inductance contribution with $\cos \varphi=0.31$.

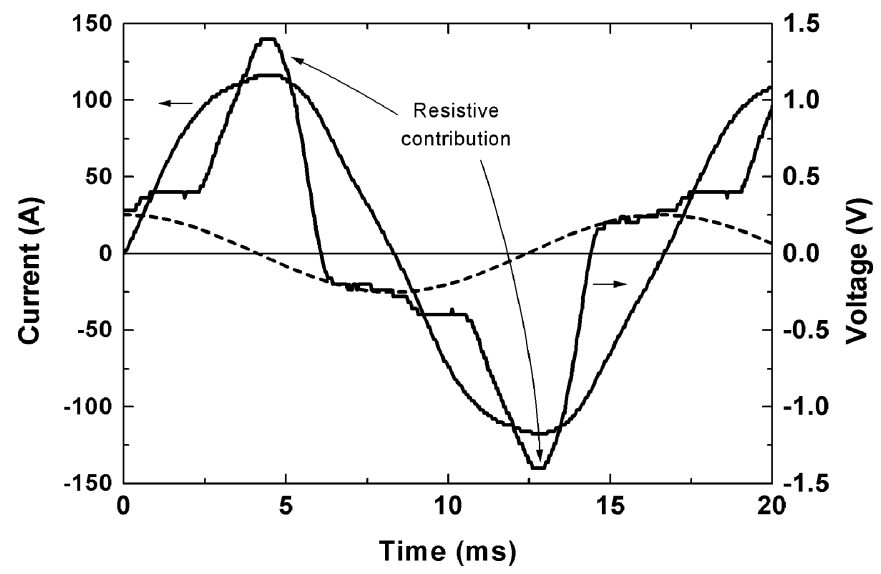

Fig. 4. Voltage and current signals for $I_{r m s}=80 \mathrm{~A}$. The dashed curve is a fitted waveform considering pure inductance contribution with $\cos \varphi=0$.

\section{B. Coil II}

In the coil II, inductively wound with tape II, the inductance is $\mathrm{L}=28.3 \mu \mathrm{H}$. The measured and the calculated voltage waveforms along with the current waveforms are shown in Figs. 5-7. Unlike the coil I, the voltage due to the magnetic flux contribution is predominant among the other contributions and the voltage waveforms display less peaks than the coil I voltage waveforms. The magnetic flux contribution is superposed with other induced voltages within the superconductor (hysteretic, coupling, and dynamic losses) making difficult the transition current analysis from $\mathrm{AC}$ measurements.

For the current values close to critical current of the coil the resistive contribution will grow in phase with the current, as shown in Fig. 7. Above that current level, the power loss will increase mainly because the contribution of normal state fraction until complete transition occurs and the resistance of the coil will be governed by the matrix resistivity as well as the normal state superconducting phase as function of temperature.

The total AC loss can be obtained with contribution of transport current loss, magnetization loss and self-field loss of combined AC magnetic field and AC transport current to the loss of the device. The transport current loss in the coil can be obtained by the product of these waveforms integrated during the period. The magnetization loss is not a function of the transport current

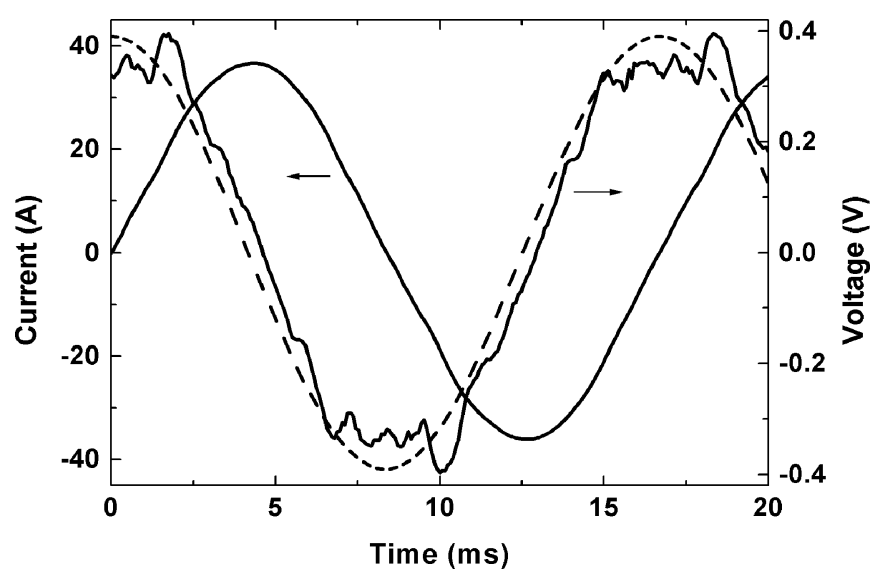

Fig. 5. Voltage and current signals for $I_{r m s}=25 \mathrm{~A}$. The dashed curve is a fitted waveform considering pure inductance contribution with $\cos \varphi=0.19$.

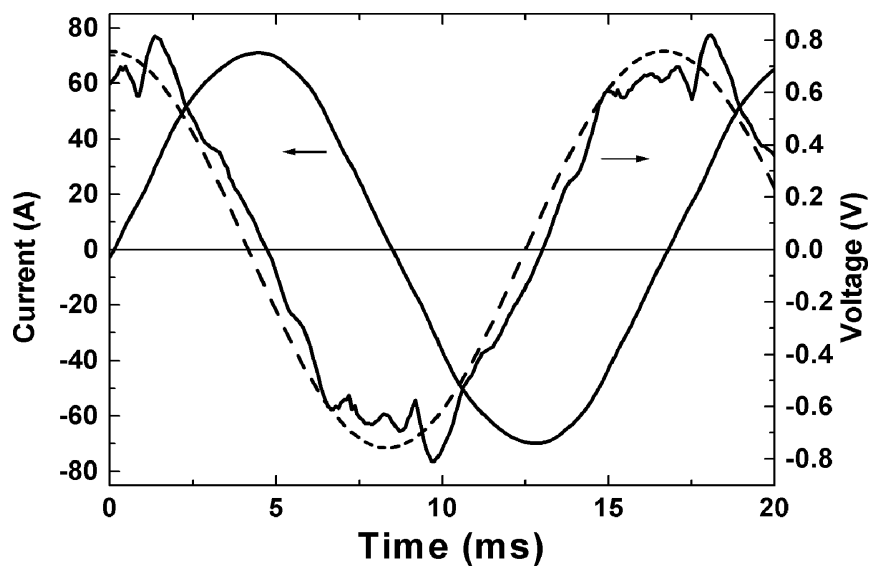

Fig. 6. Voltage and current signals for $I_{r m s}=50 \mathrm{~A}$. The dashed curve is a fitted waveform considering pure inductance contribution with $\cos \varphi=0.16$.

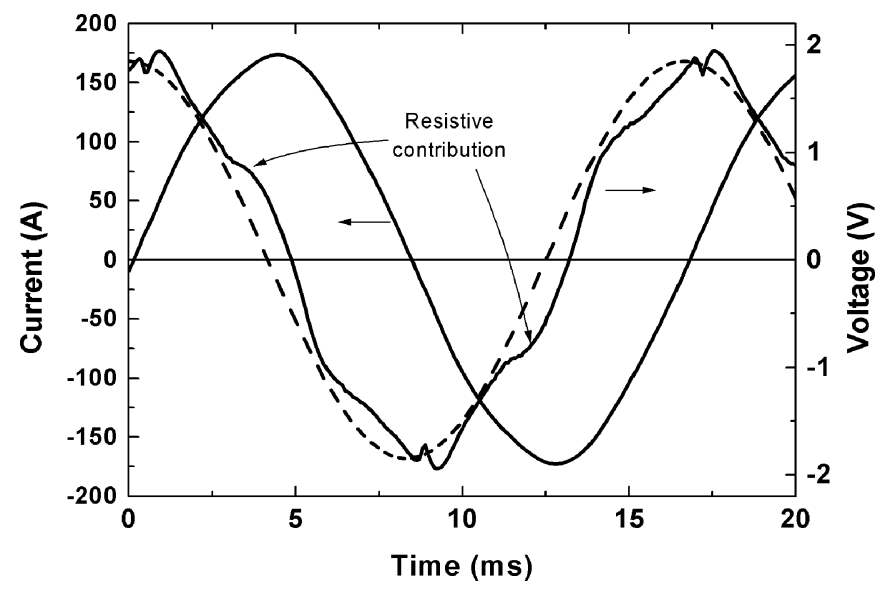

Fig. 7. Voltage and current signals for $I_{r m s}=120 \mathrm{~A}$. The dashed curve is a fitted waveform considering pure inductance contribution with $\cos \varphi=0.20$.

but proportional to the applied magnetic field and its orientation [6], [7].

The total AC loss was measured for the coil I (noninductive) in which the contribution of the magnetic flux is very low. In the coil II, the contribution of the magnetic field generated by another turns combined with transport current is more significant than the coil I. 


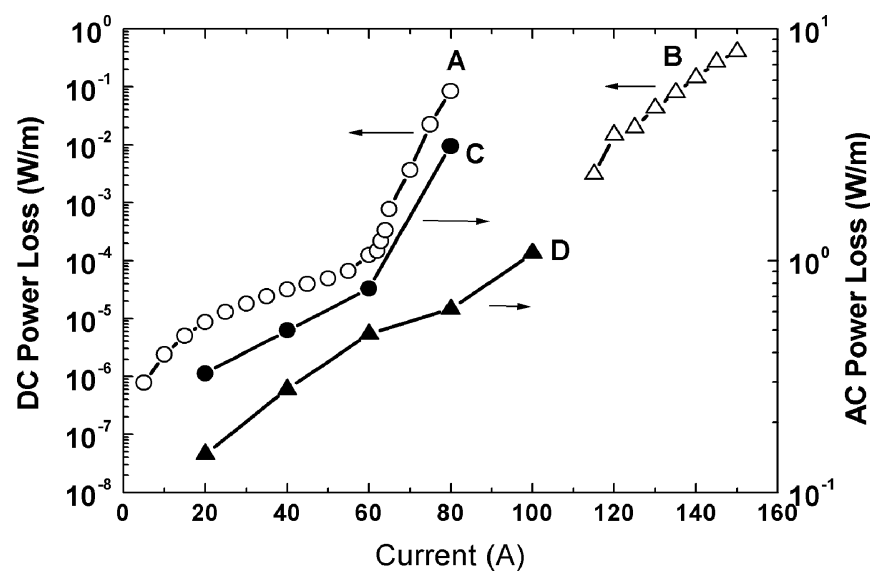

Fig. 8. DC power losses calculated from DC I-V curves for (A) coil I and (B) coil II. AC power loss measured from nitrogen boil-off mass for the (C) coil I (noninductive) and (D) coil II.

Fig. 8 shows the $\mathrm{DC}$ and $\mathrm{AC}$ power losses curves for the coils I and II. The coil I shows a smooth transition due to the bifilar arrangement in which the inter-turn applied magnetic field contribution is almost cancelled. Although the scales are significantly different we can observe that the inflection point in the AC loss curve for the coil I coincides with the inflection point in the DC power loss curve. This trend could be expected for the coil II, albeit the inflection point at that curve was not attained because of the current limit $(100 \mathrm{~A})$ that can be applied steadily by the variac.

\section{CONCLUSION}

In this work we presented the design issues and experimental methods and results of two HTS coils aiming its use in resistive SFCL construction.

The design of the HTS coils for SFCL shows good agreement with test results and the measured transition current is very close to the predicted value. The 3-D software was used to calculate the magnetic field distribution from an actual geometric model which takes into account the helical path. In comparison with the magnetic field distribution, the self and the total inductance the 2-D model previously studied we could succeed to calculate and the transition region of the conductor with more accuracy.

The analysis of the AC voltage signals from the coils included the impedance contribution from inductance and the contribution from the part of total resistance $(6.06 \mathrm{~m} \Omega / \mathrm{m})$ of the HTS conductor length in the normal state. We show that a resistive contribution to the voltage waveform in phase with the current waveform becomes the dominant contribution as the current level is increased above the critical current.

The system used for total AC loss measurements in the coils with correlation between the liquid nitrogen mass boil-off measurements and the calculated DC power losses was suitable. An inflection point is observed for the noninductive coil power loss curves both under AC and DC conditions, probably caused by the transition current from superconducting to normal state.

Further work is underway in order to evaluate the same contribution of transition current to the power loss curves for the inductive coil II and to analyze each loss contribution (hysteretic, coupling and dynamic) to the $\mathrm{AC}$ voltage and current waveforms.

\section{REFERENCES}

[1] W. Paul, M. Chen, M. Lakner, J. Rhyner, D. Braun, and W. Lanz, "Fault current limiter based on high temperature superconductors-different concepts, test results, simulations, and applications," Physica C, vol. 354, pp. 27-33, May 2001

[2] R. P. Homrich, E. R. Filho, D. G. Pinatti, C. A. Baldan, and C. Y. Shigue, "Single-phase resistive superconductor electrical current limiter," IEEE Trans. Appl. Supercond., vol. 12, no. 1, pp. 1386-1389, March 2002.

[3] M. Leghissa et al., "Development and characterization of Bi-2223 conductors for HTS transformer applications," IEEE Trans. Appl. Supercond., vol. 11, no. 1, pp. 2943-2946, March 2001.

[4] Software Amperes, Integrated Engineering Software, Winnipeg, MB, 2000.

[5] F. Darmann, S. Dou, and C. Cook, "Determination of the AC losses of Bi-2223 HTS coils at $77 \mathrm{~K}$ at power frequencies using a mass boil-off calorimetric technique," IEEE Trans. Appl. Supercond., vol. 13, no. 2, pp. 1-6, March 2003.

[6] J. J. Rabbers, B. ten Haken, O. A. Shevchenko, and H. H. J. ten Kate, "An engineering formula to describe the AC loss of BSCCO/Ag tape," IEEE Trans. Appl. Supercond., vol. 11, no. 1, pp. 2623-2626, March 2001.

[7] F. Gömöry, L. Frolek, J. Souc, A. Laudis, P. Kovac, and I. Husek, "Partitioning of transport AC loss in a superconducting tape into magnetic and resistive components," IEEE Trans. Appl. Supercond., vol. 11, no. 1, pp. 2967-2970, March 2001. 